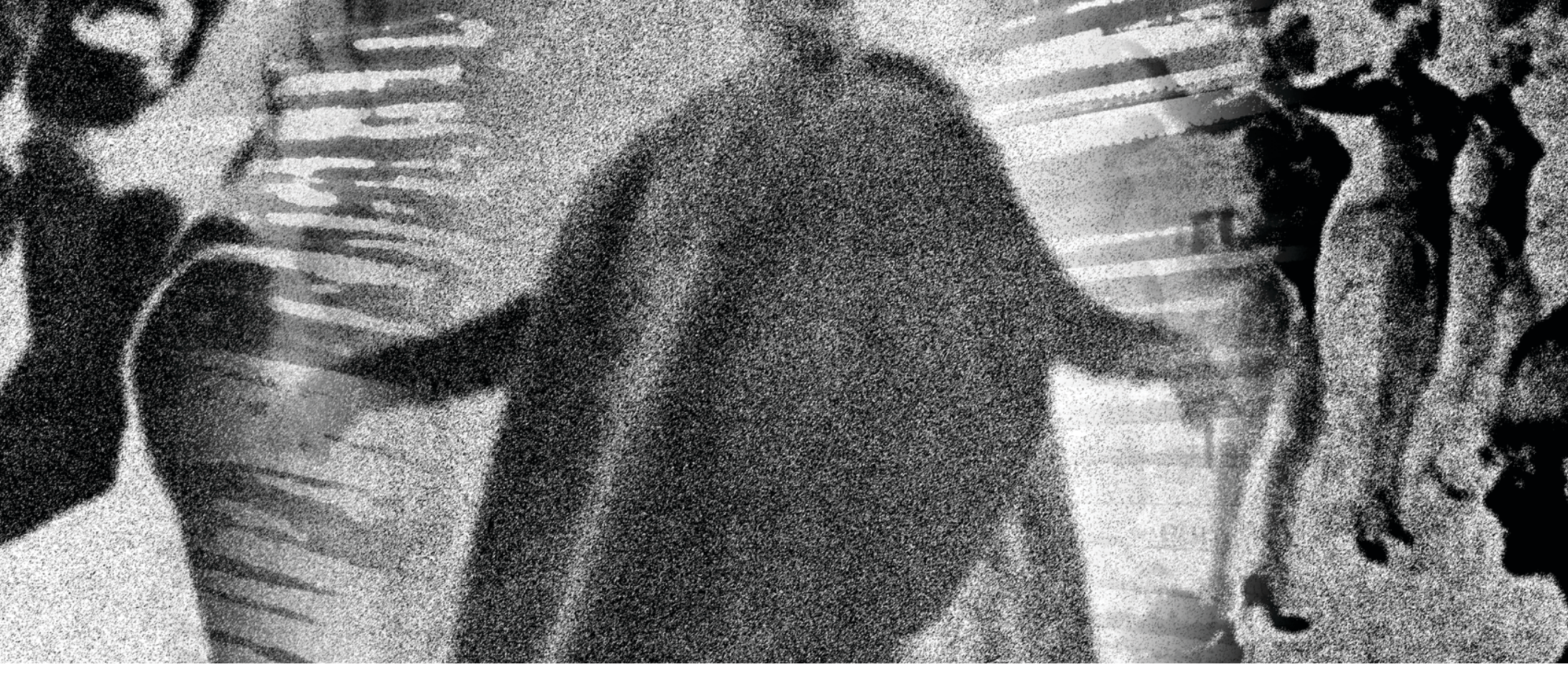

\title{
CIRCUITOS MEDIÁTICOS Y RELATO DE GÉNERO EN EL MEDIO ORIENTE DURANTE LOS AÑOS SESENTA: EL CASO DE KUWAIT ${ }^{1}$
}

MEDIA CIRCUITS AND GENDER NARRATIVE IN THE MIDDLE EAST DURING THE SIXTIES: THE CASE OF KUWAIT

Por

Ángela M. González Echeverry ${ }^{2}$ Gulf University for Science \& Technology [Universidad del Golfo de Ciencia y Tecnología] gonzalezecheverry.a@gust.edu.kw Orcid: http: / / orcid.org/0000-0002-6635-4763 
Resumen: El siguiente artículo se propone identificar los alcances del discurso mediático en el establecimiento de imaginarios culturales de género dentro del marco de descolonización y modernización de naciones en el Medio Oriente, tomando el caso de Kuwait. A través de una lectura de imágenes de anuncios publicitarios provenientes del periódico Kuwait Times durante la década de los sesenta, se explicará cómo el cambio de los centros de poder en la nueva conformación geopolítica además de dar el impulso histórico a Kuwait para formularse como una nación democrática dio también paso a la mediación informativa, cuya plataforma es la creación de productores y consumidores de información dentro de esta zona. En consecuencia, la democracia y la modernidad interpelaron un diálogo que se refleja en las imágenes del periódico, exponiendo las complejas y múltiples realidades del relato de género en Kuwait en la década de los sesenta y su sucesiva relevancia hoy día.

Palabras clave: Medio Oriente, género, Kuwait, años sesenta, Kuwait Times.

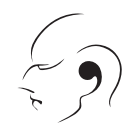

Abstract: The following article aims to identify the scope of media discourse in the establishment of gender cultural imaginaries framed by decolonization and modernization of nations in the Middle East, taking the case of Kuwait. Through a reading of images of advertisement from the Kuwait Times newspaper during the sixties, it will be explained how the political mediation hand in hand with cultural dissemination is building a narrative in parallel with a shift of the power centres in the geopolitical configuration of the region. As an independent nation, Kuwait was exposed to cultural discourses coming from informative mediation, whose platform is the creation of producers and consumers of information within this area. Consequently, democracy and modernity interpelled a dialogue that is reflected in the images of the newspaper, exposing the complex and multiple realities of Kuwait in the 1960 s and its successive relevance today.

Keywords: Middle East, gender, Kuwait, sixties, Kuwait Times.

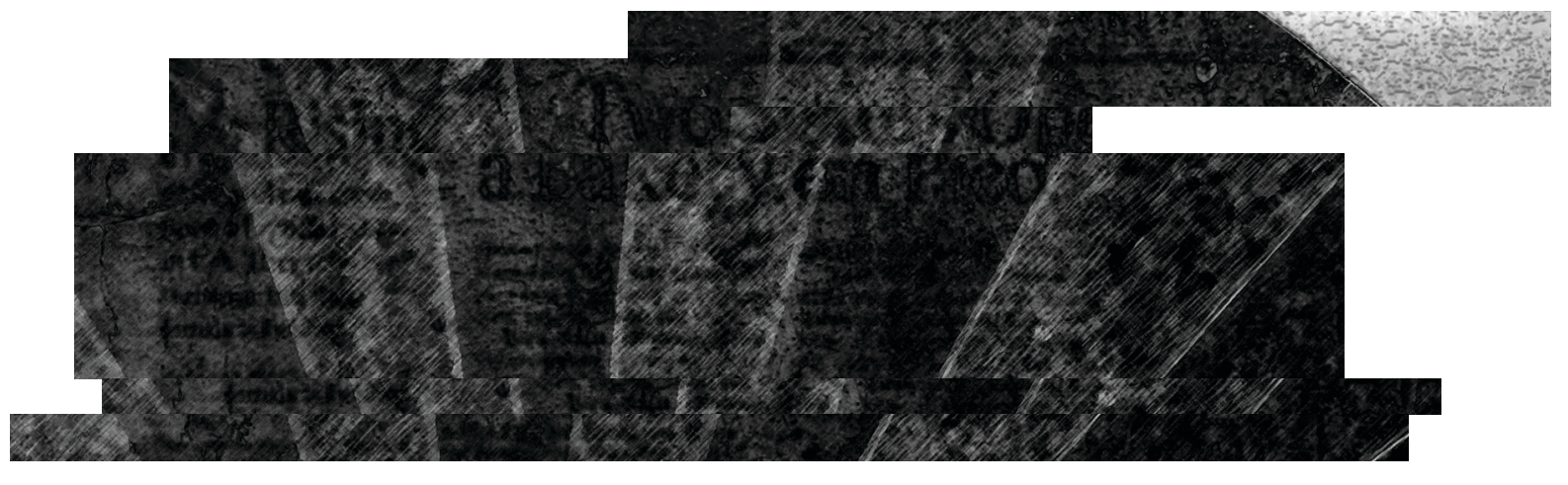


All for Kuwait and

Kuwait for all

Todos para Kuwait y

Kuwait para todos

Memorial Museum,

Kuwait 2020.

\section{Introducción}

A través de una lectura de imágenes de anuncios publicitarios provenientes del periódico Kuwait Times durante la década de los años sesenta se explicará cómo la mediación política de la mano de la difusión cultural va construyendo un relato nacional que busca ajustarse a los lineamientos legales, sin perder de vista las complejas y múltiples realidades de una nación recién consolidada. Este artículo por tanto se propone identificar los alcances del discurso mediático en el establecimiento de imaginarios culturales de género dentro del marco de descolonización y modernización de naciones en el Medio Oriente.

Las imágenes del periódico seleccionadas al igual que las historias de las mujeres que aparecen en sus páginas evidenciarán que el discurso de género más allá de ejercer un papel en el mercado de consumo de productos, dentro de una economía rebosante, marca el camino de la representación a través de la suplantación de una estética que ya no será exclusivamente árabe. De acuerdo a esto, el presente estudio busca, a través de la lectura de las imágenes seleccionadas, exponer el desplazamiento de los centros culturales de la zona en la segunda mitad del Siglo XX y así entender cómo los países del Golfo - y en especial Kuwait- van adoptando modelos que en estado de constante tensión exigen la negociación de valores culturales en los que la representación femenina se imbrica con una estética que interpeló la modernidad y adaptó la democracia como tejido geopolítico de la región.

En un área de siete mil millas cuadradas, Kuwait ${ }^{3}$ con una población de 4.200.000 habitantes - de los cuales solo el 50\% son ciudadanos kuwaitíes-es un territorio que amalgama múltiples e intrincadas fisuras o aberturas culturales que continuamente entran en diálogo y en fricción. Estas fisuras que han sido llamadas heterogeneidades ${ }^{4}$, no son ajenas a otros países del Golfo y han sido examinadas por autores como Halim Barakat (1993), cuya tesis señala que después de la caída del Imperio otomano, las sociedades/naciones árabes emergentes han estado en un constante y permanente influjo entre polos opuestos: "past versus future, East versus West, tradition versus modernity, secred versus secualr, etnicity versus class solidarity, unity versus fragmentation, and so on" (12) [pasado versus futuro, Occidente versus Oriente, tradición versus modernidad, lo sagrado versus lo secular, la raza versus la solidaridad del clan, la unidad versus la fragmentación y así sucesivamente]. 
En la actualidad, la complejidad de Kuwait también se le atribuye a la convivencia con expatriados que llegan de diversas regiones culturales y lingüísticas. Aunado a lo anterior y en busca de respuestas a las complejidades culturales de la región con sus intrincados fraccionamientos, el crecimiento económico imprevisto, tras el descubrimiento del petróleo a finales de la década del cincuenta, es sin duda un factor determinante de la realidad cultural kuwaití y de su valor geopolítico.

Según fuentes gubernamentales en cabeza de Kuna (Kuwait Agency News) los primeros hallazgos de pozos de petróleo datan de 1938, aunque las exportaciones comerciales se iniciaron en forma a mediados de los años cuarenta. Ya para 1953, Kuwait era el mayor productor de petróleo en el Golfo. Sus reservas se estimaron en $20 \%$ de las reservas mundiales conocidas. No obstante, solo hasta los cincuenta los beneficios provenientes de la explotación petrolífera se concretaron. Fatma Hussein, figura relevante del activismo feminista, escritora y destacada personalidad de los medios de comunicación de Kuwait, además líder de la resistencia durante la guerra del Golfo en 1990 declara, citada por Aubry (2017) que "Although Kuwait was one of the earliest countries in the Gulf to discover oil, we didn't witness the rapid development brought on by its wealth until the late 1950s" [Aunque Kuwait fue uno de los primeros países del Golfo en descubrir petróleo, no fuimos testigos del rápido desarrollo derivado de su riqueza sino hasta finales de la década de 1950].

Sobre el mismo asunto Al Ebraheem Al-Sabah señala que: "The discovery of oil radically transformed Kuwait's socio-economic life. The influx of expatriate workers $[\ldots]$ the opening of schools, the use of mass media and the education of some Kuwaitis abroad, all had a tremendous impact in society" (2017, p. 88) [El descubrimiento del petróleo transformó radicalmente la vida socioeconómica de Kuwait. La afluencia de trabajadores expatriados [...] la apertura de escuelas, el uso de los medios de comunicación y la educación de algunos kuwaitíes en el extranjero, tuvieron un tremendo impacto en la sociedad].

Jacqueline Ismael (1982) sostuvo que el influjo de trabajadores foráneos en la década de los cincuenta fue resultado de la expansión de un mercado de consumo considerable y nuevo que tenía para entonces pocas restricciones. En otras palabras, las transformaciones derivadas de la conocida revolución del petróleo además de asegurar un Estado de bienestar (Al Ebraheem Al-Sabah, 2017), dieron confianza

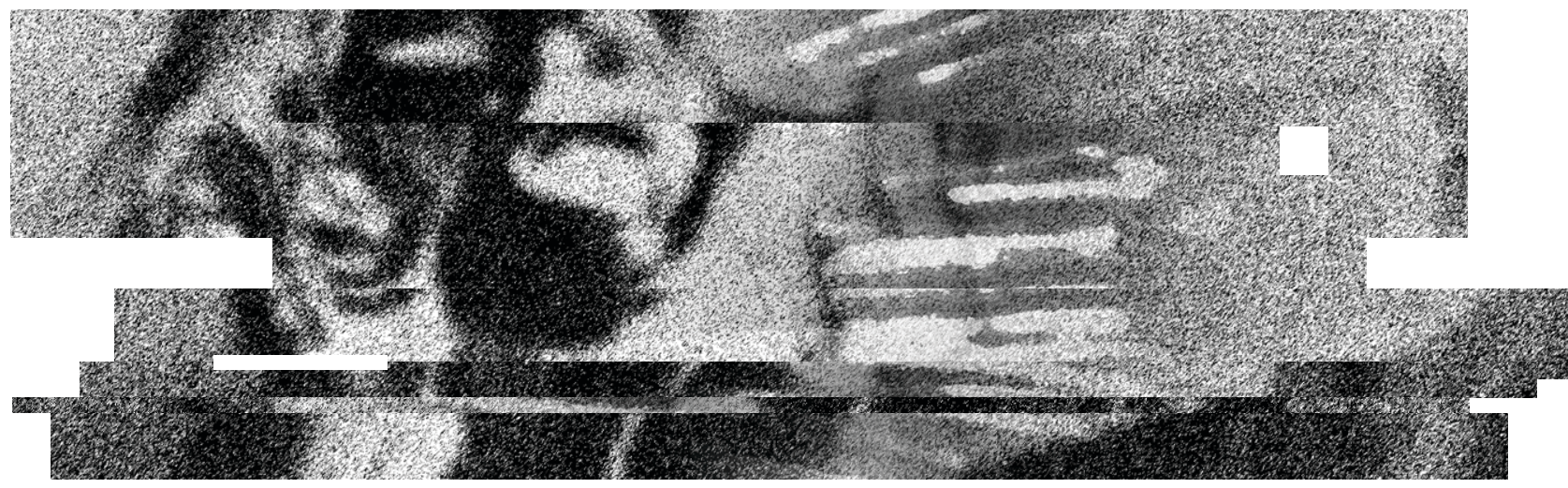


y capacidad financiera a la familia real de los Al-Sabah para emprender el proceso de descolonización y formación de la nación a mediados del Siglo XX. Pese a todos estos cambios, la casa real buscó adoptar políticas de redistribución de las ganancias provenientes de la "nueva riqueza petrolera" (Al-Sabah, 2017, p. 88).

En este sentido es evidente que los cambios en Kuwait no solo llegaron con un estilo de vida resultante de los recursos materiales "vivienda, transporte y alimentación", sino como lo explica Muhammad Al Haddad (citado por Al-Sabah, 2017), los valores, las tradiciones y las prácticas culturales absorbieron el impacto de la "cultura occidental, especialmente la democracia” (p. 88). Rejwan (2003) apunta que:

\begin{abstract}
Westernization, often used as another term for modernity, is a construct that has certain characteristics associated with Western cultural values not necessarily related to modernization. [...] modernity refers to a set of related attributes that are a consequence of the industrial revolution and its social and economic effect on society ${ }^{5}$.
\end{abstract}

El boom económico trajo de igual manera innegables tensiones que alcanzaron la zona de los países del Golfo, por cuanto los modelos de nuevas naciones que se estaban formando tuvieron que repensar los valores tradicionales propios mientras se demandaban nuevos lineamientos procedentes de las democracias occidentales. Modernización y occidentalización parecieron entenderse como una misma línea (Rejwan, 2003), o por lo menos como dos entidades dependientes y derivadas la una de la otra. Esta situación determinó en gran medida la emergencia de capas o fragmentos invisibles que poco a poco dieron paso a las contradicciones de esta nueva nación, requiriendo procesos de acoplamiento cultural y legal que no fueron sincrónicos para todos los sectores de la sociedad.

Kuwait antes del proyecto nacional era una región habitada por tribus y clanes. Esta composición social y política multidimensional determina la respuesta al proyecto de nación y al plan de democracia adoptado como forma de gobierno por la familia real. Particularmente para las mujeres la modernización y la democratización dio lugar a un discurso mayormente contradictorio que se manifiesta en las leyes y en los discursos culturales, pero que al mismo tiempo hizo surgir disyuntivas de género. Al respecto Zaha Alsuwailan dice que:

The response to modernity has fallen into two different trends: the Islamist/tribal element of Kuwaiti society viewed modernity - or the Westernization associated with it-as a dangerous concept that corrupted women's status in Kuwait and steers them away from their proper place. The advocates of modernity, on the other hand, see modernization as is not harmful, and believe in women working beside men to accomplish its goals. In other words, while the Islamists view modernization as contrary to Islamic values in all aspects, more liberal Kuwaitis think that it is a necessity for a developing country (2006, p. 147) ${ }^{6}$. 
Por ende, los cambios fueron de grandes proporciones, sin que esto significara dejar en seguida los modelos culturales tradicionales. En efecto, la transformación que empezó en los años cincuenta persiste aún y puede intuirse una suerte de modernización inconclusa que se exterioriza en las contradicciones al interior de la sociedad, incluso en el marco de las democracias occidentales.

\section{Estado del arte}

Tomando entonces aquellas contradicciones que dan origen a una sociedad en pleno proceso de modernización y democratización hay que subrayar la relevancia de las mujeres en la construcción del proyecto nacional en Kuwait, no solo como sujetos de derechos, sino como hacedoras y reproductoras culturales. Hasta antes del boom petrolero, era la industria de las perlas y el comercio con África oriental e India lo que mantenía la economía de la zona y, por otra parte, la ausencia del hombre, que debía irse de casa por largos periodos hizo que las mujeres "not only managed large households, but came to control family affairs and finances" [no solo administraran en gran medida los hogares, sino que también controlaran los asuntos familiares y las finanzas] (Fatma Hussein citada por Alex Aubry, 2017).

A pesar de esta preeminencia femenina en la vida socioeconómica y familiar, la participación en política y el reconocimiento de una igualdad en el ejercicio pleno de derechos será una cuestión hasta hoy discutida. La transformación a la democracia con la que se institucionalizó la nación de Kuwait en los años sesenta propuso como se verá más adelante, un principio de igualdad ciudadana que si bien entra en la carta constitucional no se evidencia en muchas de las prácticas políticas cotidianas. No obstante, la modernización y el establecimiento de la democracia favorecieron la entrada de discursos de género que se materializaron en una economía de mercado que moldeó una estética femenina paradójica e intrincada.

Algunos sectores críticos de los derechos de las mujeres argumentan que aun hoy día el posicionamiento de las mujeres en Kuwait sigue siendo desventajoso, especialmente en lo concerniente a derechos políticos y de autorrepresentación. Para ejemplificar esta desventaja quienes luchan por la igualdad recuerdan que solo hasta el año 2005 fue nombrada la primera mujer en un ministerio en Kuwait, la doctora Masouma Al-Mubarak, ministra de Planeación y Desarrollo. Noticia que exaltaron activistas de los derechos de las mujeres y la prensa internacional. Así reportó PBS NewsHour dicha elección: "It was not until May 2005, through the pull of the progressive ruling family and family-appointed ministers, that parliament allowed women to vote and stand for election" (30 de junio de 2006). [Solo hasta mayo de 2005 y gracias a la influencia de la progresista familia real y los ministros designados por la familia real, que el parlamento permitió que las mujeres votaran y se presentaran a las elecciones]. 
Mary Ann Tétreault, autora de Stories of Democracy: Politics and Society in Contemporary Kuwait (2000) -referenciada en este mismo artículo de prensa- manifiesta que las mujeres desde la aprobación de la Constitución (1962) estuvieron "standing behind a closed door" [paradas detrás de una puerta cerrada] porque a ellas: "weren't allowed in as equal partners. And now the door is open, the sun is coming in, and these women are marching out" (PBS NewsHour, 30 de junio de 2006) [no se les permitía entrar como iguales. Y ahora la puerta se abre, el sol está saliendo y estas mujeres están marchando].

En este orden de ideas hay que reflexionar también sobre las relaciones de Kuwait con Gran Bretaña y señalar que siempre fueron de mutuo entendimiento y que este estrecho lazo cultural y político es lo que explica la existencia de un periódico en inglés, en una nación que habla mayormente árabe. Esta relación se consolidó con la firma del protectorado acordada por ambos países en 1899. Dicha cercanía incluso data de antes cuando el comercio de la India hacia Gran Bretaña se hacía a través de Kuwait, según lo establece Abu-Hakima en A Modern History of Kuwait (1982).

Al final de la Primera Guerra Mundial no hubo dudas sobre el afianzamiento de Gran Bretaña como la fuerza política y cultural más importante en la zona del Golfo. A pesar de dicha proximidad, después de la Segunda Guerra Mundial los británicos ya no pudieron proseguir con su voluntad imperial y los jeques del Golfo alcanzaron una nueva importancia estratégica con la puesta en marcha de la explotación del petróleo. Fue entonces el momento de repensar desde una perspectiva emancipadora, la naturaleza política y cultural de dichos territorios. Zaha Alsuwailan escribe: "The British colony could no longer sustain a policy of colonization, especially after the loss of India and its failure to maintain administrative control over Kuwait" (2006, p. 56) [La colonia británica ya no podía mantener una política de colonización, especialmente después de la pérdida de India y del fracaso en el mantenimiento del control administrativo sobre Kuwait].

El establecimiento de una economía próspera, el repliegue de Gran Bretaña en la zona y el influjo de ideas anticoloniales crearon el momentum para lo que sería Kuwait. Así fue como en 1961, el emir Abdullah Al-Salim Al-Sabah ${ }^{7}$ (1895-1965) convocó a elecciones para una Asamblea Nacional Constituyente con la idea de consolidar a Kuwait como nación independiente. Muchos fueron los movimientos políticos al interior y en la comunidad internacional y el 6 de enero de 1962 fue promulgado el texto Act. No. 1 que contenía las reglas básicas de gobierno durante un periodo transicional, que duró hasta el 29 de enero de 1963 cuando se inauguró la Primera Asamblea Nacional (Majlis al-Umma). Los quince miembros del gabinete fueron nombrados por el emir, quien conservó el derecho de disolver la Asamblea Nacional por voluntad propia. En este espacio político se formularon los principios fundamentales de la nación: 1) el mantenimiento de la libertad y la dignidad, 2) el establecimiento de una unidad nacional, 3) el logro del desarrollo y el progreso, 4) la prevalencia de los intereses de Kuwait, 5) el llamamiento a colaborar con 
las naciones árabes hermanas, y 6) la cooperación con Naciones Unidas en el fortalecimiento de la seguridad y la paz mundial (minutas del discurso pronunciado por el emir en la Asamblea Constitucional, 2 de enero de 1962). En efecto, Kuwait se pensó como una democracia y su Constitución aprobada dio un gran paso al proyecto pionero de primer país independiente y soberano del Golfo.

Así fue como una poderosa clase mercantil se consagró al desarrollo de la economía y al fortalecimiento del Estado de bienestar moderno. En el momento en que Kuwait alcanzó su independencia, la izquierda y el nacionalismo panárabe dominaban el discurso político de Medio Oriente y esto se reflejó plenamente en los principios constitucionales que ajustaron la nueva nación. El emir necesitaba legitimar el nuevo estatus de Kuwait y su propio papel como dinastía gobernante, en particular frente a las amenazas de Irak que afirmaba que Kuwait era parte suya y debía ser territorio anexado. En ese entonces las fuerzas sauditas y británicas se movilizaron e Irak tuvo que reconocer las fronteras internacionales de Kuwait.

Ahora bien, mientras Kuwait entraba en una etapa de modernización al interior estableciendo una Constitución democrática, en el exterior su esfuerzo se concentró en consolidar relaciones diplomáticas tanto con países árabes como con Occidente. Estas iniciativas culminaron con el ingreso del país a la comunidad internacional, así como también se fueron asegurando futuros aliados. "Kuwait became a member of the United Nations and other international institutions" [Kuwait se convirtió en miembro de las Naciones Unidas y de otras instituciones internacionales] (Alsuwailan, 2006, p. 91). Así pues, qué mejor oportunidad de afianzarse como nación creciente con enorme capacidad económica que presentarse al mundo a través de su primera embajada en Washington ${ }^{8}$. La misión diplomática abrió sus puertas en 1966, tres años después de su ingreso a las Naciones Unidas.

Durante los primeros años de la década de los sesenta Kuwait adoptó una nueva bandera, apareció el primer dinar -moneda que reemplazó la rupia india- y el país ingresó a la Liga Árabe (1961), todo esto con motivo de impulsar la nueva nación. Por su parte, el sector de la educación introdujo importantes reformas sociales y aumentó los espacios de formación universitaria. Para Aida Arasoghli (1986): "In 1960, the first six Kuwaiti women received their college degrees from Cairo University. In 1963, Loulua al-Qutami, a pioneer of women's rights, founded the Kuwaiti Women's Cultural and Social Association. In 1970, the number of college graduates rose to 215, and 5 held graduate degrees" [En 1960, las primeras seis mujeres kuwaitíes recibieron diploma universitario otorgado por la Universidad de El Cairo. En 1963 Loulua al-Qutami, pionera de los derechos de la mujer, fundó la Asociación Cultural y Social de Mujeres Kuwaitíes. En 1970 el número de graduadas universitarias aumentó a 215, y 5 obtuvieron títulos de posgrado]. 
Se crearon además medios de comunicación autónomos, revistas con contenido político y publicaciones culturales de circulación regional. Por ejemplo, la revista Al-Arabi - que se enfoca en aspectos culturales del mundo árabe- tuvo su primera edición en diciembre de 1958 y uno de sus fundamentos iniciales era la divulgación de la ideología del panarabismo, constituyéndose en un modelo cultural e informativo a seguir:

Since its establishment, the magazine has witnessed steady modernization in topics and sections, in line with the technological advancement of the day. Kuwait used to be in the past an example in the gulf region in the realms of culture and art (Arab Times, 19 de mayo de 2013).

Se llevaron a cabo eventos culturales de poesía, teatro y moda. El gobierno apoyó financieramente las artes. Se estableció un canal estatal de televisión con cobertura de eventos globales, cines con lo último de Hollywood y espectáculos culturales de los que se hablaba en toda la región. Bien conocidos son los grandes conciertos y las visitas de celebridades como Andy Warhol. En otras palabras, Kuwait parecía ir a la vanguardia de todos los países del Golfo, considerado líder de la región y paradigma de desarrollo de políticas democráticas libertarias y progresistas.

\section{Género y modernización}

Estas iniciativas parecen tener resonancia en la formación de "a new elite cultured class, consisting of independent bedouin, sons of merchants, and former seamen and divers who gained positions in the state apparatus, and who had no tribal affiliation but were loyal to the state as $\operatorname{such}^{10}$ (Al-Sabah, 2017, p. 109), que sin duda alineó la composición social y política de Kuwait, impactando su sistema de gobierno, sus leyes y sus prácticas culturales. Vale la pena destacar que, hasta principios del Siglo XX, Kuwait se conformaba por cuatro grupos humanos: la familia real, los comerciantes, los jefes de tribus y el resto era una población de "comerciantes, artesanos, marineros, buscadores de perlas, pescadores" (Al-Sabah, 2017, p. 109), que llegaron a Kuwait provenientes de tribus menores y perdieron sus conexiones anteriores. Dentro de esta élite destacan también las mujeres que ya empezaban a prepararse para la vida laboral y cultural. Aida Arasoghli (1986) señala que las mujeres pasaron de ser el $1 \%$ de la fuerza laboral en 1957 a ser el 3,2 \% en 1975; cifras que motivaron una búsqueda de equidad y una legislación que en vías de modernización debían garantizar y promover un clima de derechos políticos y laborales a las mujeres.

Después de establecido el contexto de la nueva nación de Kuwait, sus cambios, tensiones y al mismo tiempo los avances de las políticas de modernización es posible distinguir dos corrientes de pensamiento predominantes en la política y en la vida de Kuwait que determinarán el alcance del discurso de género proveniente de las imágenes del periódico Kuwait Times que serán analizadas “a conservative tendency and 
a progressive tendency" (Al-Sabah, 2017, p. 109). Los resultados de estas divisiones sustentarán la ejecución de modelos legislativos y culturales que se materializarán en los discursos mediáticos derivados de la difusión cultural que va construyendo aquel relato nacional de nación nueva, independiente y legislativamente democrática. Este proceso de ejecución del Estado moderno impactó obviamente a las mujeres, quienes se encontraban en proceso de adaptación y reinscripción de espacios culturales y políticos.

Modernization affected greatly Kuwaiti women in urging them to revise their status in society. As a result, many Kuwaiti women attempted to improve their social and political status. The more active women took advantage of the social shift and used it to develop their position in Kuwaiti society. At the beginning, they adapted modernization for both its innovation and Westernization aspects. They developed their educational status by attending universities and studying abroad, and at the same time they adapted Western cultural influences, which were most visible in their discarding of the veil and their imitation of Western dress. After that, they looked to other societies, especially Westernized Arab societies such as Egypt and Lebanon, and inspected women's emancipation movements there and began to question their position in their own country (Alsuwailan, 2006, p. 117$)^{11}$.

Una clara muestra de inconformidad toma forma en el activismo feminista, en las defensoras de los derechos políticos de las mujeres como Badria al-Awadhi, renombrada experta en ley sharia; Loulua al-Qutami, fundadora de la Asociación Cultural y Social de Mujeres Kuwaitíes; Noreya al-Saddani, activista de los derechos políticos de la mujer en Kuwait y Fatma Hussein, la primera mujer en tener un programa de radio sobre asuntos femeninos. La presencia de este grupo de activistas, por nombrar solo algunas, indica el acogimiento de un discurso de género que se fue instaurando en los espacios culturales y mediáticos. De cierta manera, estas mujeres personificaron la modernidad y promulgaron valores democráticos como la igualdad y la participación. Sus modelos culturales fragmentan tanto la estética exclusivamente árabe como el discurso de género tradicional.

En este punto, vale la pena mencionar la experiencia de Fatma Hussein, quien cuenta que cuando salió de Kuwait para estudiar en la Universidad de El Cairo comenzó a definir su identidad como feminista. Empezó un proceso de cuestionamiento especialmente relacionado con las convenciones que marcaron las anteriores generaciones de mujeres: "I wore the abaya until I was 23. We used to leave Kuwait wearing it and remove it on the flight to Cairo" [Llevé abaya hasta los 23 años. Solíamos salir de Kuwait usándola y ya en El Cairo nos la quitábamos] (Aubry, 2017). Solo se la ponía de nuevo cuando regresaba a su casa en Kuwait para las vacaciones. Fatma decide abandonar por completo el uso de esta prenda cuyo significado es todavía una marca de género para las mujeres de Kuwait. Así, resume este cambio de estética: "I remember my family was initially shocked when I arrived at the airport, 
but I didn't give them a chance to comment and acted as if everything was normal” (Aubry, 2017) [Recuerdo que mi familia se sorprendió inicialmente cuando llegué al aeropuerto, pero no les di la oportunidad de comentar y actué como si todo fuera normal].

Mujeres como Fatma, que salieron de Kuwait a estudiar o que simplemente viajaron a otras latitudes, se fueron apropiando de un modelo cultural y de género de características inéditas en Kuwait. La estética tradicional procedente de la religión y de la organización tribal se fragmentó adicionando capas más complejas a aquel discurso de género contradictorio con los fundamentos de la democracia y de la nueva nación.

Si bien los beneficios de la bonanza petrolera se redistribuyeron en la modernización de Kuwait, hay quienes expresan que modernizar viene de la mano del establecimiento de una nación secular. En el caso de las mujeres, dicha modernización también tomo forma en el cambio de paradigmas culturales con relación al rol que estas debían cumplir en la sociedad y la discusión se encaminó al establecimiento de los límites de su participación en la vida política y el pleno ejercicio de sus derechos, de hecho "modernization affected greatly Kuwaiti women in urging them to revise their status in society" (Al-Sabah, 2017, p. 116) [la modernización afectó enormemente a las mujeres kuwaitíes al instarlas a revisar su estatus en la sociedad]. La Constitución (1962) fue enfática en declarar derechos igualitarios: "justice, freedom and equality are pillars of Society; co-operative and fellow-feelings are the firmest bonds binding all citizens" (art. 7) [justicia, libertad e igualdad son pilares de la sociedad; cooperación y compañerismo son los lazos más firmes que unen a todos los ciudadanos].

La declaración de igualdad entre hombres y mujeres parece un paso hacia una sociedad moderna. No obstante, hay quienes ven en esta iniciativa de igualdad y el llamamiento a la participación de las mujeres una justificación que subraya el concepto de deber patriótico, en cuya esencia hombres y mujeres son responsables de preservar la nación. La igualdad conviene en la medida en que se hace indispensable "to use every human resource to build a nation" (Al-Mughni, 2000) [usar cada recurso humano para construir una nación]. Asimismo, se reclamó una legislación que se ajustara a los principios de igualdad y que promoviera la participación de las mujeres en lo público sanando la situación de desventaja creada por "legal codes, tradition and norms” (Al-Mughni, 2000) [los códigos legales, la tradición].

\section{Circuitos mediáticos: el caso del Kuwait Times}

Lo que se estudiará a continuación para entender y contextualizar las imágenes seleccionadas para esta investigación tendrá en cuenta los estudios de Al Ebraheem Al-Sabah sobre constitucionalismo y las investigaciones recientes que han aportado diversos enfoques a los estudios del Medio Oriente, principalmente con relación a Kuwait y en específico sobre género. Nociones como igualdad, expatriados, 
modernización y sharia, serán pertinentes para el entendimiento del discurso mediático en Kuwait. En este orden de ideas, se inserta el análisis del relato de género que aparece en el periódico Kuwait Times en la década de los sesenta, no sin antes mencionar que los antecedentes del origen moderno de la prensa en Kuwait según William Rugh (1987) datan de 1928.

Fue evidente el carácter cosmopolita del contenido de los medios en Kuwait hasta 1991, como lo apunta Rugh (1987), cuando la prensa y en general los medios de comunicación masiva regresan a los asuntos internos como centro de la información, dejando el carácter panarabista y cosmopolita que había definido la prensa en inglés como respuesta a una población de expatriados (vinculados en su mayoría a la explotación petrolífera) provenientes en un alto porcentaje de países árabes, India y Pakistán. De hecho, la importancia y el impacto de los medios son palpables después de que Kuwait se conformara como nación independiente. Es en este momento en el que surge la prensa en inglés.

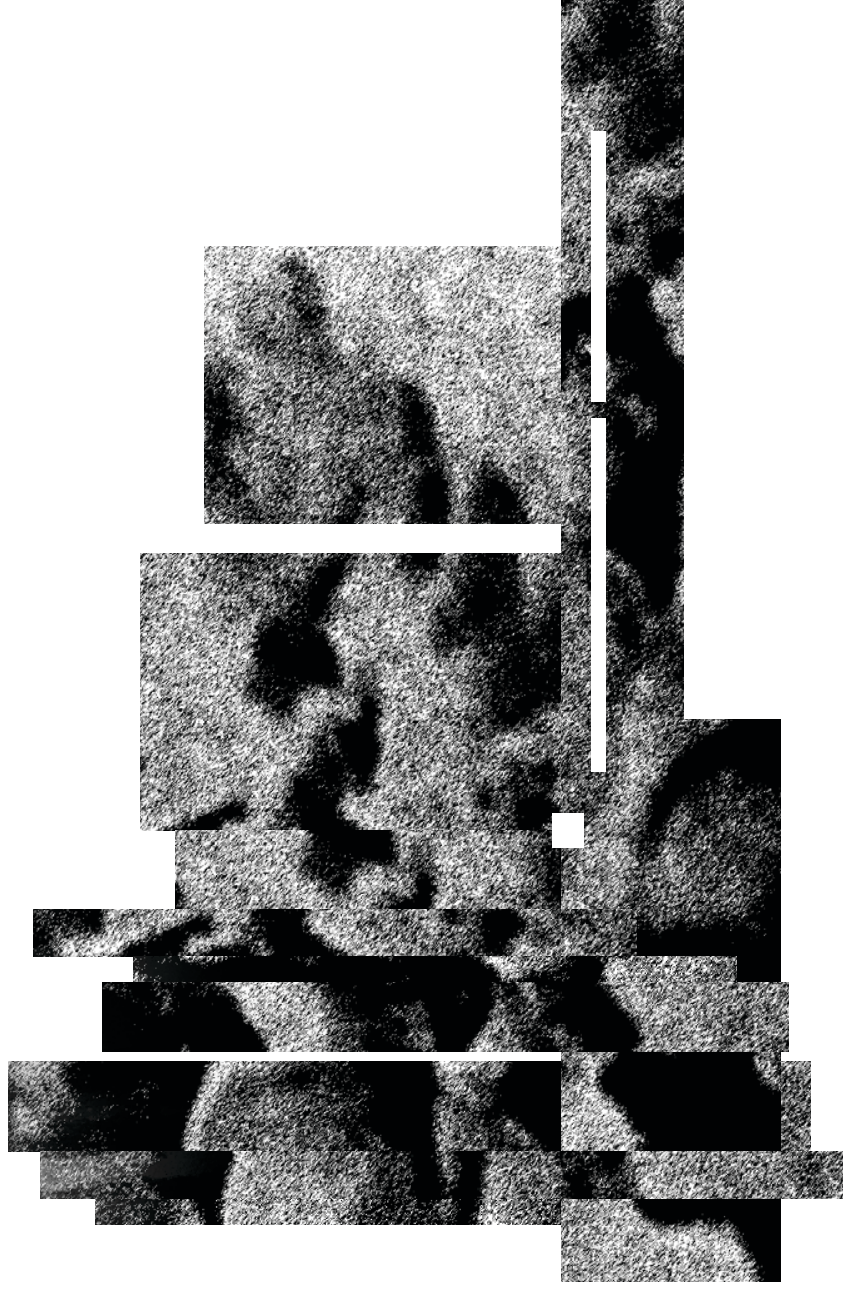

Kuwait Times aparece en 1961, recogiendo un imaginario cultural sugerente, que se estructuró sobre las bases de un sistema mediático de productores y consumidores de información. Es por esta razón que era imprescindible entender el marco de la independencia de Kuwait y sus garantías democráticas impulsadas por el propio emir Abdullah Al-Salim Al-Sabah (1950-1965), quien ya para enero 8 de 1962 había promulgado un decreto que garantizaba la libertad de expresión hablada y escrita como un preámbulo de lo que sería la Constitución futura. Ahora bien, persiguiendo los ideales de modernización y democratización que se acordaron en la Asamblea, el artículo 36 de la Carta Política (1962) dictó que:

Freedom of opinion and of scientific research shall be guaranteed. Every person shall have the right to express and propagate his opinion verbally, in writing or otherwise, subject to the conditions and stipulations specified by law ${ }^{12}$.

Es evidente entonces que los fundamentos democráticos de la nación revertidos desde sus orígenes en la Constitución protegen la libertad de opinión. Este reconocimiento expreso no obstante tiene una salvedad y es la obligación de supeditarse a las regulaciones legales. Básicamente, la ley es la instancia reguladora del derecho constitucional (libertad de expresión e información) y la fuente de la ley, no exclusiva pero expresa, es la sharia ${ }^{13}$. Al respecto $\mathrm{Al}$ Ebraheem Al-Sabah apunta que: 
Freedom under Shari' a is different from the concept of freedom in theWest. In Shari'a there must be a balance between freedom and responsibility based upon the injunctions to "Commands what is right and forbid what is evil" and "Do no harm to yourself or others" (2017, p. 141) ${ }^{14}$.

En esta encrucijada se encontraron no solo los juristas de Kuwait sino toda una tradición de pensadores que se ha dado a la tarea de distinguir lo bueno de lo malo. Siendo el islam la religión del Estado de Kuwait y la sharia "la fuente principal de la legislación” (Constitución art. 2). Según este principio doctrinario los derechos que se estaban pactando no solo debían atender a los requerimientos de la modernización, sino también las necesidades políticas y económicas de la nueva nación. En este entramado legal hay que destacar que la declaración de la Constitución sobre la libertad de expresión pertenece en la práctica al grupo de derechos y deberes públicos, siendo el marco fundamental para la actividad de los medios de comunicación en cuyo centro se halla la prensa.

La expansión de los procesos de modernización, como ya se señaló, fue suministrando infraestructura: vías, transporte, escuelas y vivienda y provocó grandes cambios en los referentes culturales. La riqueza venida del petróleo impuso un estilo de vida diferente que, aun con sus detractores - al considerar todos estos cambios como un primer paso a la occidentalización de la sociedad kuwaití-, impulsó valores culturales y modelos estéticos que encontraron espacio en los medios de comunicación y que se fueron materializando en las imágenes que se distribuían en los periódicos, en los anuncios publicitarios, en las carteleras de cine y en los eventos sociales y culturales. Para algunos pensadores la modernización fue una forma de penetración de la cultura occidental. Para otros la occidentalización es otro modo de llamar a la modernización, que generalmente se vincula con la ejecución e implementación de valores asociados a Occidente, que no siempre corresponden con la modernización (Rejwan, 2003).

Lo anterior ofrece el tejido para examinar el relato de género contenido en las imágenes femeninas del periódico, estableciendo un primer paradigma dentro de la corriente principal de Kuwait Times durante la década de los años sesenta y que tiene que ver con una estética predominantemente no árabe. Como ya se mencionó, la ideología panarabista desempeñó un papel fundamental en los orígenes de la nación de Kuwait. Ahora, no se puede perder de vista que el impacto del periódico en el cual aparecen las imágenes supera las fronteras de Kuwait, en virtud del liderazgo que este país tenía en la distribución de información y contenido cultural en la región del Golfo. A través de una emergente red aeronáutica ${ }^{15}$ (1954) se distribuían los periódicos. Por tanto, con la formación de la nación y el establecimiento de un
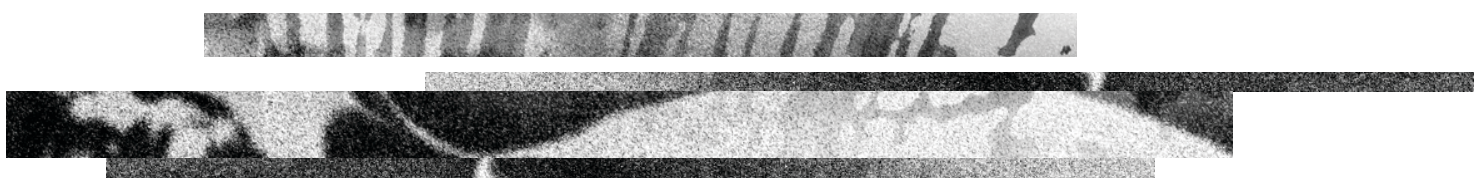
marco constitucional vinieron espacios culturales y políticos para las mujeres en Kuwait que cambiaron en apariencia el paradigma de género e incorporaron una estética diferente que entraría en discusión y en desuso en las últimas décadas del siglo veinte. Al respecto Muhamad S. Olimat en su artículo "Women and Politics in Kuwait” (2009) argumenta que la amplia gama de libertades para el pueblo de Kuwait contenidas en la Constitución fue fuertemente influenciada por la tradición constitucional de los Estados Unidos y Gran Bretaña, sin olvidar el gran influjo de la jurisprudencia islámica.

En este orden de ideas, la declaración de igualdad tuvo enormes implicaciones en la vida práctica de la nación, fundamentalmente en la educación y en el empleo remunerado, sin que esto significara escapar en la práctica de situaciones contradictorias. Sin embargo, más allá de lo cotidiano, uno de los reclamos constantes en el logro de la igualdad ciudadana es la ausencia de las mujeres en la vida política, cuyo efecto está directamente relacionado con la aprobación de la ley electoral 35 de 1962. Esta norma definió el derecho al voto en los siguientes términos: "every kuwaití male of twenty one years of age" (Olimat, 2009, p. 200). Olimat (2009) concluye que en virtud de esta norma las mujeres fueron no solo excluidas de la esfera política sino confinadas a sus hogares.

Los derechos políticos de las mujeres son fundamentales en el cambio de paradigma y en la conformación del Estado moderno de Kuwait. El artículo I de la ley electoral (1962) como lo señala Muhamad S. Olimat (2009) establece que los derechos de voto están restringidos a ciudadanos kuwaitíes alfabetizados mayores de veintiún años en contraposición con el artículo 29 de la Constitución (1962) que dicta: “todas las personas son iguales en dignidad humana y en derechos públicos y deberes ante la ley sin distinción de raza, origen, idioma o religión”.

Con base en el artículo de la ley electoral de 1962 se presentaron varios proyectos legislativos para otorgar a las mujeres sus derechos electorales. No obstante, el Ministerio de Asuntos Islámicos emitió un fallo sobre la validez del proyecto de ley. Este fallo declaró que: "the nature of the electoral process befits men, who are endowed with ability and expertise: it is not permissible that women recommend or nominate other women or men" (Ahmed Aly Khedr, 2019) [la naturaleza del proceso electoral corresponde a los hombres, que están dotados de capacidad y experiencia: no está permitido que las mujeres recomienden o nominen a otras mujeres u hombres].

La legislatura controlada por hombres que reguló la participación política de las mujeres las mantuvo en buena medida en sus roles tradicionales hasta que en el 2005 la Asamblea aprobó el artículo I de la ley electoral (35 de 1962), determinando que: "every adult Kuwaiti citizen, aged 21, has the right to vote, except a naturalized citizen, who has not been in that status for at least 20 years" [todo ciudadano kuwaití adulto, de 21 años, tiene derecho a votar, excepto un ciudadano naturalizado, que no 
ha estado en este Estado durante al menos 20 años] con la salvedad de que la elección a un cargo político o el voto de una mujer kuwaití debe corresponder y adherirse plenamente a los dictados de la sharia. Nuevamente las inconsistencias vuelven a desempeñar un papel fundamental en lo referente a las múltiples e intrincadas fisuras o aberturas culturales que se traslapan en este país del Golfo.

\section{Imágenes y discurso de género}

En los años sesenta las mujeres de Kuwait se vieron en la tarea de imaginarse a sí mismas fuera de la órbita habitual y percibieron de forma directa la naturaleza de otras estéticas y de modelos culturales alternativos. Indiscutiblemente, el flujo de información se estructuró sobre la base de una prensa protegida legalmente y sobre la iniciativa constitucional del derecho a la igualdad. Todo esto demuestra no solo las contradicciones del proceso de modernización de Kuwait sino también, la tensión entre una nación con valores religiosos arraigados en la tradición islámica y una nación cuya economía impuso intercambios de consumo y producción llegados de fuera. En estas circunstancias políticas, las mujeres tuvieron alternativas culturales que penetraron a través de fuentes como el periódico Kuwait Times, de aquí la importancia de este espacio de análisis. Zaha Alsuwailan apunta que la respuesta frente a la modernización se concretó en dos sectores distintos:

[...] the Islamist/tribal element of Kuwaiti society viewed modernity -or the Westernization associated with it- as a dangerous concept that corrupted women's status in Kuwait and steers them away from their proper place. The advocates of modernity, on the other hand, see modernization as is not harmful $\left(2006\right.$, p. 147) ${ }^{16}$.

Ambas posiciones de la sociedad se enfrentaron a la idea de corresponder con el islam los valores de la modernización, incluyendo el rol de las mujeres como pilar del desarrollo de la nación por una parte y, por otra, se abordó la modernización y el papel de las mujeres dentro de este proyecto como un camino contrario a las creencias y prácticas del islam.

Si bien la modernización se cristalizó en forma de infraestructura, vías, edificios, colegios y bienes de consumo, la creación de un marco legal por su parte también demostró una intención modernizadora. La etapa de ajuste se hizo recurriendo a la contratación de un número significativo de expatriados para trabajar en todos los sectores y asimismo sucedió con la incorporación de modelos culturales. En el caso del periódico se tuvo que recurrir a las agencias informativas internacionales que suplieron la demanda de reporteros, columnistas y corresponsales. En este contexto, Kuwait Times encaja en el proceso de modernización que presupone el reconocimiento y la importancia de fuentes alternativas, cuyo contenido viene de afuera, es en una lengua extranjera y tiene por destino a una audiencia que habla, lee y consume información en inglés. 
Las agencias de noticias internacionales eran las que escribían y puntuaban en su mayoría la agenda informativa. En esta época se pasó de agencias europeas como la Agence France-Presse (AFP) a la Associated Press (AP) de los Estados Unidos. Kuwait no contaba con corresponsales todavía que reportaran directamente los acontecimientos. De hecho, la imposibilidad de producir información de primera mano situó a Kuwait dentro del grupo de naciones receptoras de información y fue hasta mucho después cuando Kuwait pudo tener sus propios hacedores de noticias. En efecto, Kuwait sabía del mundo, pero el mundo poco sabía de Kuwait. Estas circunstancias definirán los modelos y discursos mediáticos que se ajustaron por tanto a los contenidos recibidos. Por ende, el tema de la autorrepresentación será controlado, mediado y adaptado conforme la nación se modernizaba.

A continuación, se presentan algunos ejemplos de discurso visual publicados a principios de los años sesenta por el Kuwait Times, en los cuales las figuras femeninas son el centro de campañas publicitarias de objetos como bolígrafos, cigarrillos y relojes. La clasificación de las imágenes se realizó gracias al acceso que se tuvo de los periódicos conservados en los archivos de la Biblioteca Nacional de Kuwait y a la colaboración del profesor Mauricio Duarte quien trabaja en una amplia investigación sobre la prensa en Kuwait. El material no está disponible digitalmente, así que se obtuvieron gracias a la conservación de la memoria histórica de Kuwait que hace la biblioteca. Sin embargo, hay que hacer la salvedad de que no hay una secuencia disponible completa de toda la década de los sesenta, por cuanto al momento de la invasión iraquí a Kuwait, la biblioteca y sus archivos sufrieron importantes daños y pérdidas.

Las primeras imágenes que aparecen a continuación fueron escogidas de las páginas del diario que corresponden al año de 1961. La selección va de la mano con el proceso legal anteriormente estudiado y demuestra cómo desde los inicios tanto del periódico como de la nación moderna hay una transferencia de valores culturales y estéticos que redefinen los límites y los modelos de género. Este discurso foráneo va penetrando también los reclamos y reposa en las expresiones de las activistas de los derechos de las mujeres en Kuwait.

Así, las mujeres que aparecen en los anuncios llaman la atención por la pose adoptada que representa en simultáneo una mujer cosmopolita, que necesita el regalo o el cigarrillo para pertenecer al mundo de lo inolvidable, lo placentero y lo exquisito que le otorgan los productos anunciados. Atrás quedaron las imágenes de mujeres con vestimenta tradicional o exhibiendo una actividad conforme con las tradiciones sociales de Kuwait. En contraposición a un sistema impuesto por el régimen tribal o religioso, en el cual la reputación del hombre está directamente relacionada con la protección y la separación de las mujeres de la vida pública, las imágenes ofrecen comportamientos nuevos y estéticas disímiles que en nada se compadecen con lo que Zahra Freeth señala como imperativo social: 
[...] nothing is considered more unseemly than for a woman's actions or behavior to be the subject of town gossip, even in a comparatively innocent way, and the veil has allowed women to preserve their anonymity when they leave their houses. If rumor or gossip should seriously cast reflections upon the virtue of a woman of good family, the woman is ruined (1956, p. 84$)^{17}$.

Ahora bien, lo que hay que resaltar es que las prácticas culturales tradicionales como el valor de la reputación y la protección dada por el velo, son reinscritas con la circulación de información proveniente de fuentes mediáticas. Por una parte, están las tradiciones y por otra, la fuerte influencia de la modernización estatal. Como ya se discutió, el lenguaje de la modernización trae consigo el lenguaje estético y cultural de Occidente. Este enfrentamiento comporta no solo tensiones, sino también un diálogo que va restructurando la forma de entender el género y los modelos a seguir en asuntos estéticos (Figura 1 y Figura 2).

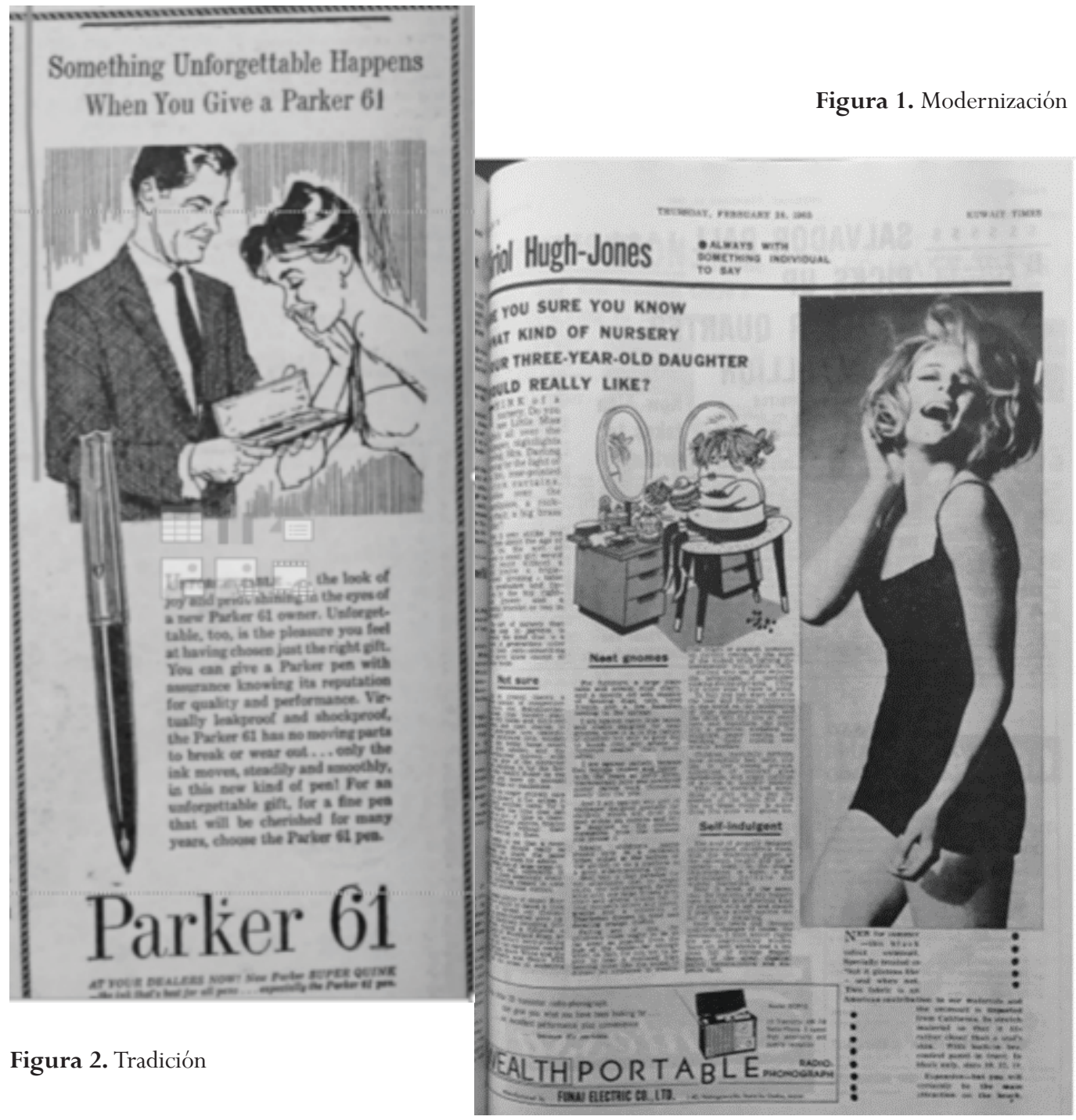


Las siguientes imágenes son explícitas en la promoción de las vacaciones ideales en las cuales mujeres y hombres disfrutan por igual de los placeres del espectáculo presenciado. Una atmósfera extranjera promete contagiar a los visitantes de una alegría traviesa y equipara la ópera con los carnavales de tierras exóticas como Brasil (Figura 3). En las páginas del periódico contrastan los anuncios publicitarios con imágenes que promocionan la música en Kuwait para amantes del espectáculo y del placer de bailar, incluyendo a las mujeres como protagonistas que hondean insistentemente sus faldas y vestidos (Figura 4). Confort y sabor a cargo de mujeres sofisticadas y sonrientes. Atras quedó la uniformidad. Sin embargo, no se puede asumir un desmantelamiento cultural, más bien lo que se percibe es una adaptación problemática que refleja el cambio de paradigmas en la región y la reinscripción de la mujer árabe a los paradigmas imperfectos de un mundo que empieza a globalizarse gracias al intercambio de productos, a los flujos migratorios y a la economía de consumo.

Figura 3. Baile extranjero

Figura 4. Música y baile tradicional

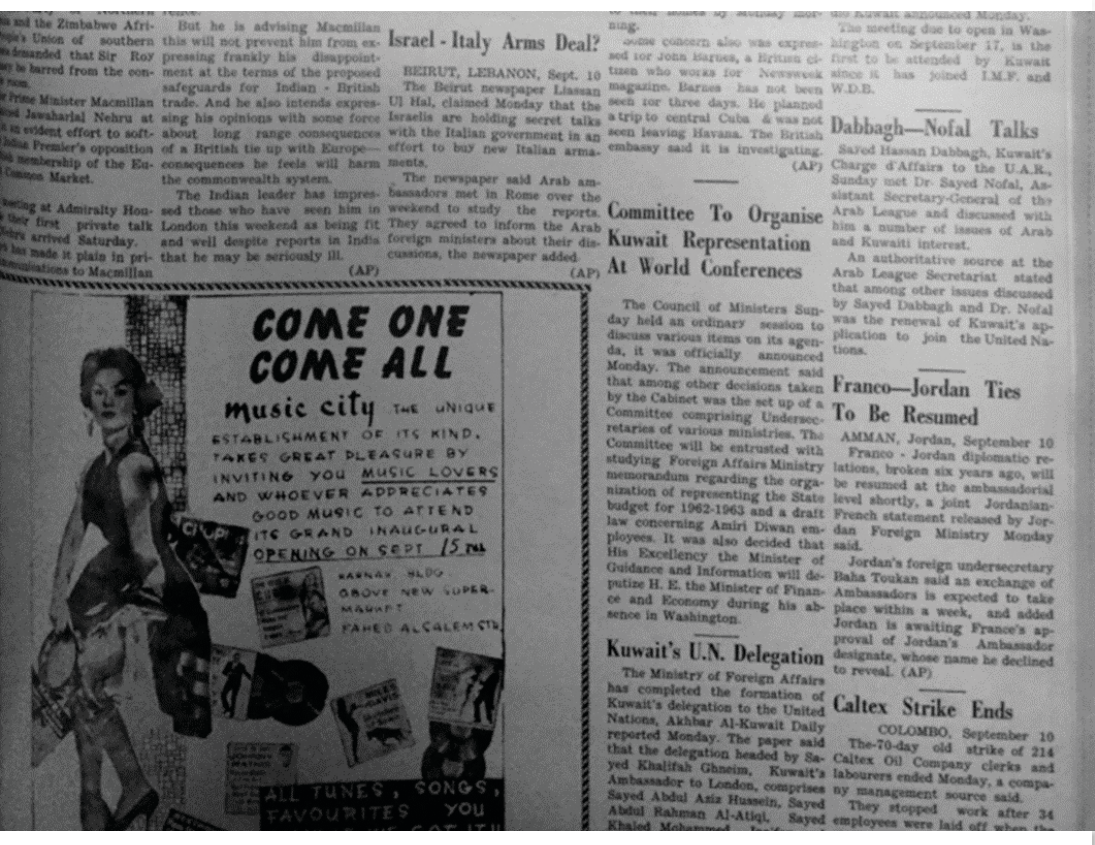

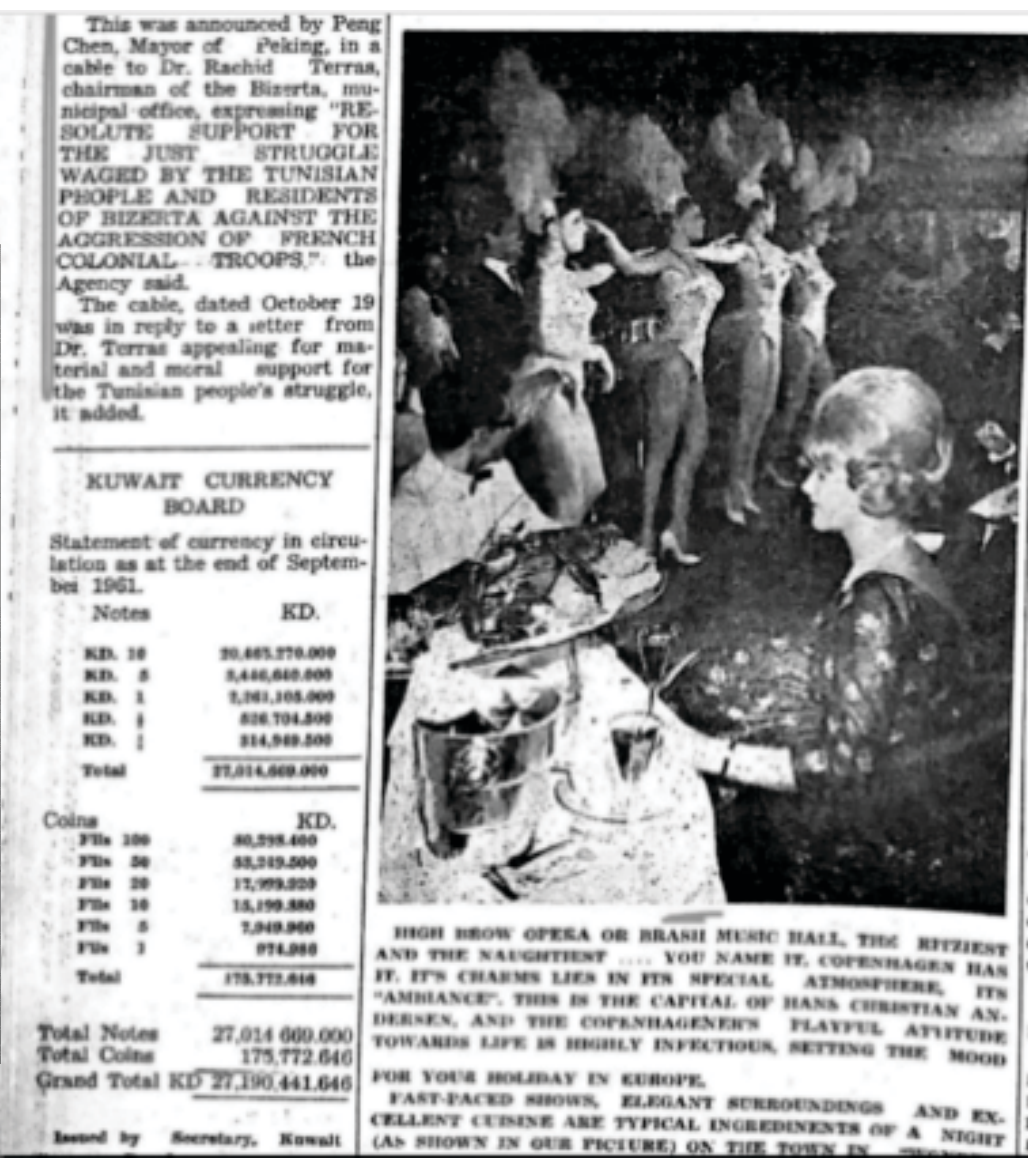

Kamal Nath (1978) escribe que "the Kuwaitis modernized their life-styles with astonishing speed and vigor” (p. 174) [los kuwaitíes modernizaron sus estilos de vida con asombrosa velocidad y vigor]. Ya no se trataba solamente de un estilo de vida moderno, sino también, de llenar las expectativas de la sociedad con experiencias por fuera de la zona cultural y estética. Más allá de la promoción de bienes de consumo, las mujeres se incorporaron a espacios de la modernidad en lo laboral y educativo. 
Tuvieron la oportunidad de estudiar en el extranjero y adaptarse a las influencias de sus nuevos entornos "which were most visible in their discarding of the veil and their imitation of Western dress" (Alsuwailan, 2006, p. 117) [que se hicieron más visibles retirando el uso del velo y en su imitación de la vestimenta occidental].

Su nueva posición en la sociedad serviría también para publicitar todo tipo de objetos. Sin duda, la promoción de casas móviles a precios razonables como se ve en las siguientes imágenes, debía acompañarse de mujeres hermosas y semidesnudas que escoltaran al comprador en sus viajes de trabajo. Por otro lado, llama la atención la imagen con que el periódico recibe el año de 1963: una mujer con actitud cordial personifica los deseos de prosperidad que este medio le envía al emir y a la gente de Kuwait (Figura 8). No es una mujer que lleve el atuendo tradicional de Kuwait. Por el contrario, la imagen descontextualiza lo árabe tanto en el sentido del rol que la mujer debe cumplir como de su estética. Finalmente, cabría resaltar que hay una normalización aparente de las mujeres en el espacio público y se da por entendida la interacción igualitaria de los géneros (Figura 9)

Figura 7. Autos de lujo

Figura 6. Moda

KUWArr tmess

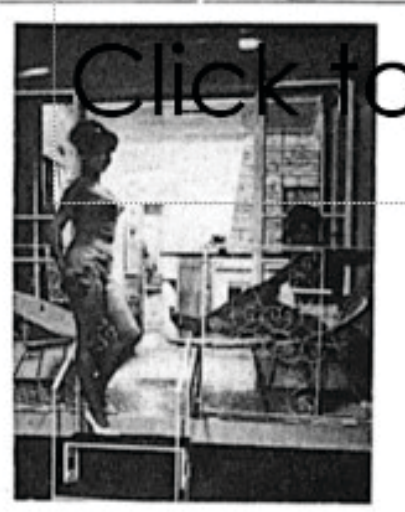

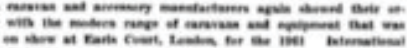

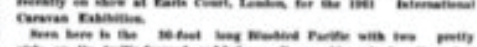

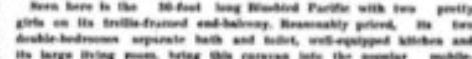

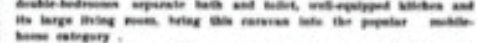

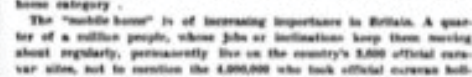

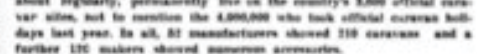

Ne w I Ne w I New I

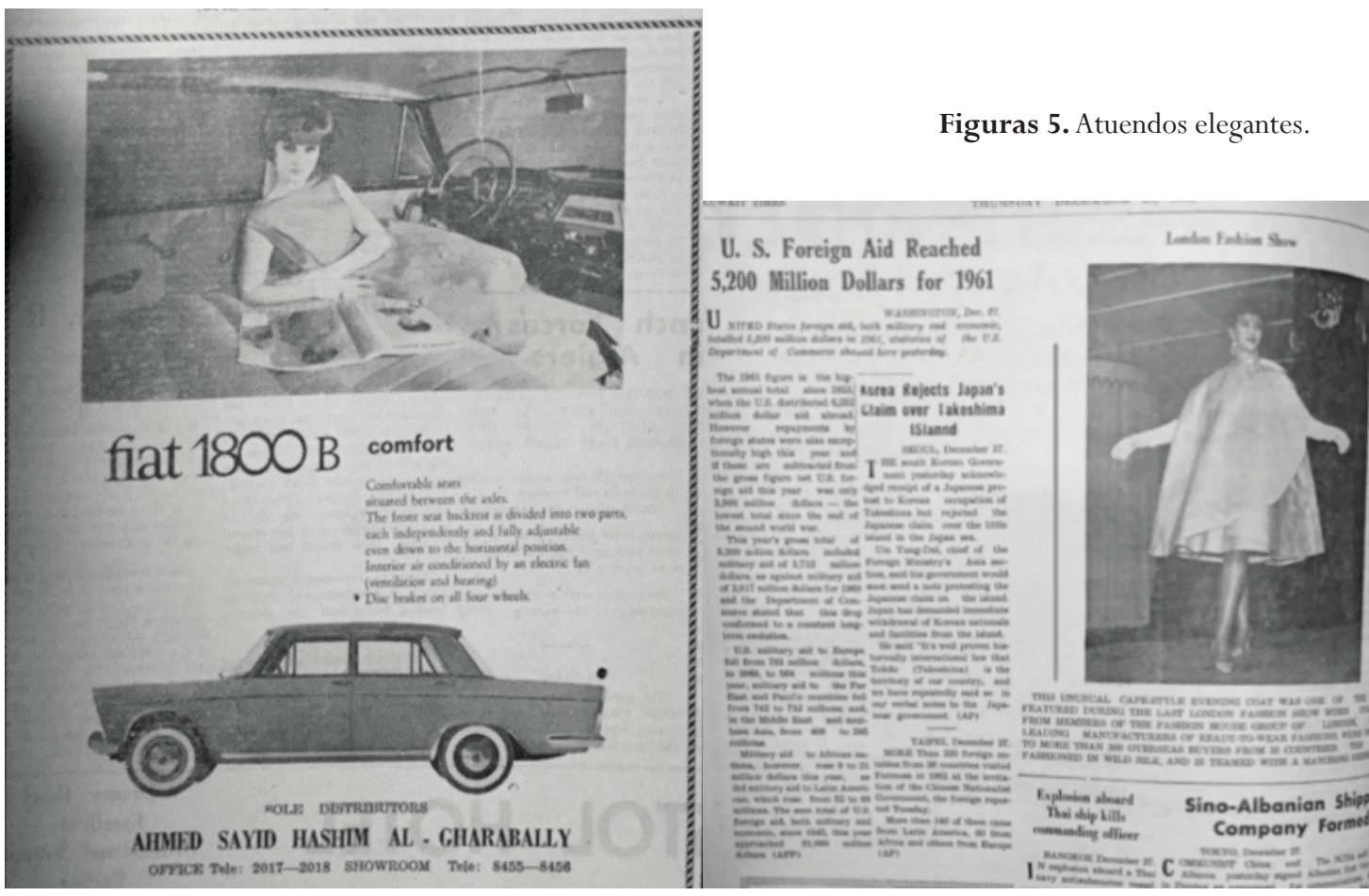

Otras imágenes hablan del precio que una mujer está dispuesta a pagar por su nueva imagen, indicando la importancia del vestido y la innecesaria habilidad en asuntos culinarios. Aquí lo relevante es conjugar la imagen de una mujer chic lista para la ocasión, aunque esto signifique un costo oculto para ella. Por otro lado, llama la atención la imagen con que el periódico recibe el año de 1963: una mujer con 
actitud cordial personifica los deseos de prosperidad que este medio le envía al emir y a la gente de Kuwait. No es una mujer que lleve el atuendo tradicional de Kuwait. Por el contrario, la imagen descontextualiza lo árabe tanto en el sentido del rol que la mujer debe cumplir como de su estética. Finalmente, cabría resaltar que hay una normalización aparente de las mujeres en el espacio público y se da por entendida la interacción igualitaria de los géneros.

Figura 8. Año nuevo 1963

Figura 9. Mujeres en el espacio público
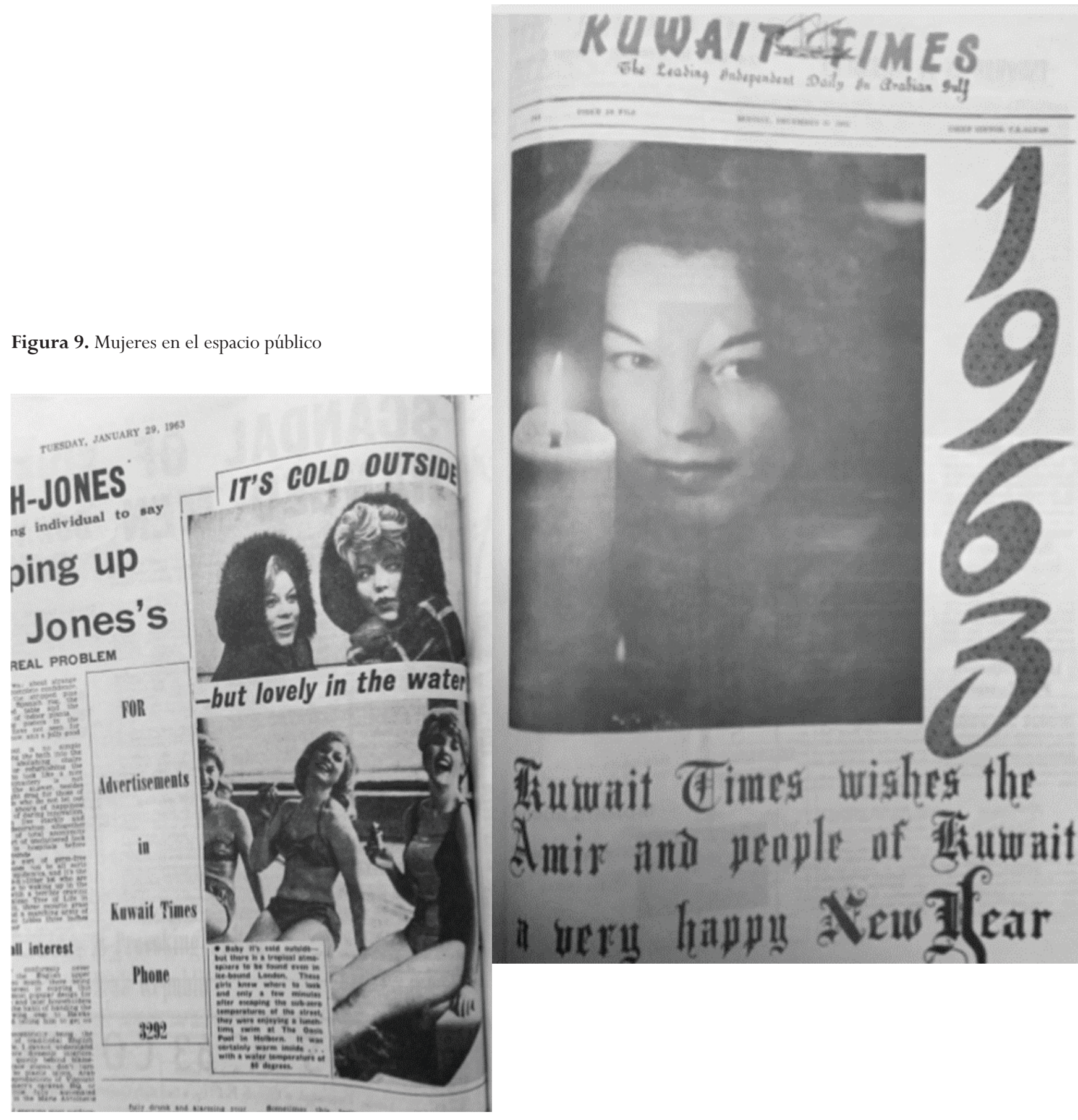


\section{Conclusiones}

Las imágenes publicitarias que se mostraron aquí del periódico Kuwait Times más allá de vender trajes de baño, biquinis y otros productos de consumo revelan los grandes cambios en el discurso de género de Kuwait a partir de la formación del Estado moderno y de su definición como nación democrática. Algunos de los feminismos tempranos se basaron en la declaración constitucional de la igualdad, no obstante, hay una clara influencia de otros discursos llegados no solo por la salida de mujeres a estudiar a otros lugares, sino también porque con el flujo de información arriban tanto ideas como modelos culturales de otras geografías. Se puede afirmar que no hay una total consistencia entre los discursos sociales y los discursos culturales, aunque la ley intencionalmente procuró acortar el abismo entre una nación regida por los principios del islam y, por tanto, por la ley sharia, y la legislación moderna promotora de una economía de consumo e intercambio.

La presencia de las mujeres en el imaginario y en el consumo cultural evidente en los anuncios de la década de los sesenta empezó su declive, como lo recuerda Maryam Hasam (1996), al señalar el retroceso de los procesos de modernización con la tendencia de finales de los años ochenta y principios de los noventa.

[...] segregation and a strict Islamic dress code have re-emerged, and the issue of the niqb (face cover) [...] I wonder what has happened to the intellectual initiative of Muslim thinkers and scholars, who should be coming up with new ideas about how to preserve our identity without abandoning social, intellectual and psychology progress (Al-Sabah, 2017, p. 181$)^{18}$.

De este modo, se construyó una narrativa cultural y estética que incorporó ampliamente imágenes femeninas provenientes de otras latitudes -no únicamente árabes- en el discurso mediático de la nueva nación. A través del periódico Kuwait Times los hablantes de inglés y en general la sociedad, obtuvieron acceso a información sobre asuntos locales y extranjeros durante un decenio en el que la geopolítica radicalizó las fuerzas y el mundo se dividió entre buenos y malos. Así, las imágenes sirven para explicar los cambios en la mediación política y aquella difusión cultural en paralelo con la construcción de un relato nacional que busca ajustarse a los lineamientos legales de la democracia, sin perder de vista las complejas y múltiples realidades de Kuwait en la década de los sesenta y su sucesiva relevancia hoy día.

Por lo tanto, es posible hablar de un desplazamiento de los centros culturales en la segunda mitad del Siglo XX, en cuyo epicentro reposa la idea de modernización proveniente de una legislatura en los albores de la nueva nación. Este giro político y cultural se reflejará en las alianzas futuras de los países del Golfo. Las imágenes y las historias de las mujeres que aparecen en las páginas del periódico más allá de desplegar el curso de una sociedad de consumo, marcan el camino de la representación a 
través de la negociación de una estética que ya no es exclusivamente árabe. Los lectores del diario comparten las experiencias de Occidente a través de valores cosmopolitas de consumo y libertad. Los paradigmas culturales marcan el camino hacia cánones estéticos que vienen de la mano la modernidad, aunque también de la occidentalización.

La información pasa por un proceso de destilación en el cual el panarabismo y los valores tradicionales de una sociedad musulmana se recomponen en virtud de una agenda democrática. Es claro que la información proveniente de los centros de poder se plasma también en el discurso cultural y estético que por medio de la prensa en inglés sugiere el tránsito de valores estéticos/sociales y la entrada en pleno de la circulación de productos culturales que se añaden como capas invisibles a la complejidad sociocultural de Kuwait.

Por último, gracias al estudio de estas imágenes del periódico en la década de los sesenta es posible advertir la construcción binaria de productores y consumidores culturales y mediáticos, cuya legitimación se basa en la formación de los nuevos órdenes mundiales donde la ocupación territorial se desplaza hacia el dominio simbólico.

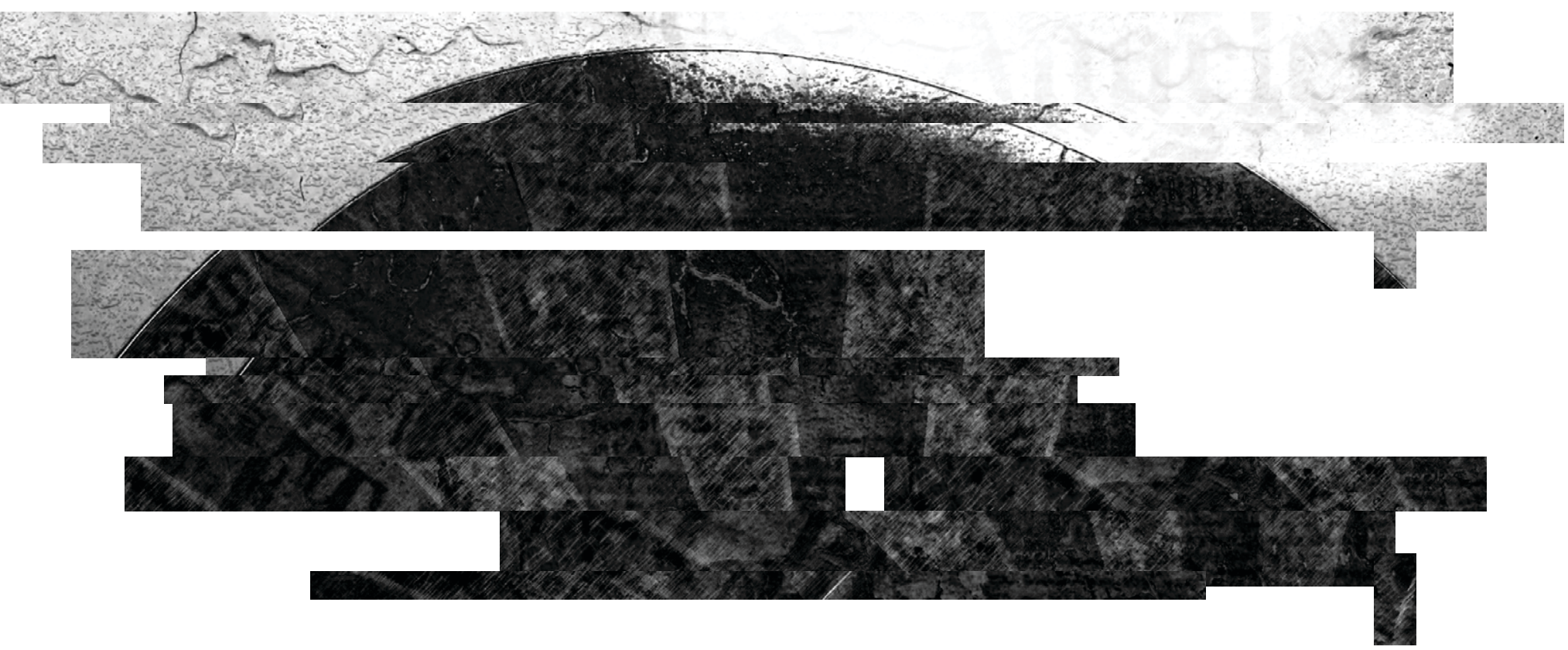




\section{Notas}

${ }^{1}$ El origen de este artículo es una ponencia presentada en la conferencia East-West Cross-cultural Relations, "Dialogs in Transition: Luso-Hispanic Cultural Production and Global South Exchanges" Varsovia, Cracovia, Bielsko Biala (Polonia) mayo 9 al 12 de 2019 cuyo título inicial fue "Imágenes femeninas occidentales del periódico en inglés Kuwait Times en los años sesenta”.

${ }^{2}$ Ph.D. En humanidades/estudios culturales de la Universidad del Estado de Arizona. Profesora de Humanidades y ciencias sociales de la Universidad del Golfo de Ciencia y Tecnología de Kuwait.

${ }^{3}$ Kuwait, a small city-state on the Persian-Arabian Gulf, has undergone massive political, economic, and social development throughout the 20th century. In spite of this, Kuwaiti rulers continue to cherish what is perhaps an impossible dream: that Kuwait can be simultaneously a 'developed' country and a 'traditional' tribally organized social formation run by an autocratic ruler. This dream is echoed in equally ambivalent pronouncements and policies regarding women, not only by representatives of the state but also by Kuwaiti citizens. Should Kuwaiti women stand side by side with men in public life as half of a modern society, or should they be secluded, subjected by, and submissive to the men in their lives as local 'tradition' demands? In this essay I argue that these two ambivalences are linked. Democratization of Kuwaiti political life has proceeded in fits and starts that parallel the uneven progress of democratization of gender relations in Kuwait. Perhaps in consequence, the politics of both kinds of democratization have become more closely linked" (Tétreault, 2001).

${ }^{4} \mathrm{Si}$ bien este concepto ha sido ampliamente usado para estudiar los fenómenos culturales de América Latina, encontramos pertinente su uso y aquí volver sobre Néstor García Canclini cuando explica las relaciones culturales entre premodernidad, modernidad y fenómenos asociados a la posmodernidad latinoamericanas. En su obra Culturas híbridas (1989) propone tres hipótesis que deben ser entendidas para el caso de Kuwait. Primera: el autor apunta a aquella incertidumbre sobre el verdadero valor y sentido de la modernidad cuyo fundamento se desprende de "cruces socioculturales en que lo tradicional y lo moderno se mezclan" (1990, p. 14). Asimismo, en Latinoamérica la modernidad trata de los espacios culturales de múltiples sectores que se encargan de "la heterogeneidad multitemporal" (1990, p. 15). Antonio Cornejo Polar también estudia la heterogeneidad en Perú, conocido es su ensayo "Escribir en el aire. Ensayo sobre la heterogeneidad socio-cultural en las literaturas andinas" (1994). Por tanto, utilizaremos aquí el vocablo heterogeneidad (tan investigado en Latinoamérica) y haremos extensivo este concepto para contextualizar en términos culturales a Kuwait.

${ }^{5}$ [La occidentalización, a menudo es utilizada como otro término equivalente a la modernidad, no obstante, es una construcción que tiene ciertas características asociadas con los valores culturales occidentales, pero no necesariamente se refiere a la modernización en sí misma. La modernidad se refiere por su parte a un conjunto de atributos derivados de la revolución industrial y sus efectos socioeconómicos en la sociedad].

${ }^{6}$ [La respuesta a la modernidad comporta dos tendencias diferentes: la tendencia islamista/tribal de la sociedad kuwaití que vio la modernidad -o la occidentalización asociada con esta modernidad - como un concepto peligroso que corrompió a 147 mujeres en Kuwait y las alejó de su rol primario y de su lugar en la sociedad. Y la tendencia donde se ubican los defensores de la modernidad, que consideran que la modernización no es dañina y que las mujeres trabajan junto a los hombres para lograr sus objetivos. En otras palabras, mientras los islamistas ven la modernización como contraria a los valores islámicos en todos los aspectos, los kuwaitíes más liberales piensan que es una necesidad para un país en desarrollo]. 
${ }^{7}$ Hakima Abu (citado por Al-Sabah, 2017) arguye que en 1752 de acuerdo con las costumbres tribales árabes Sabah I fue seleccionado como jeque de Kuwait

${ }^{8}$ La construcción estuvo a cargo del arquitecto de Baltimore Van Fossen Schwab quien diseñó un edificio modernista con arcos de inspiración islámica. En el interior Valerian Rybar diseñador de interiores de Nueva York, creó una sala de recepción con un mosaico de 27.000 piezas talladas en nogal ensambladas en tres meses por 18 artesanos que llegaron desde El Cairo. Además, la embajada tenía una espectacular sala Omayyad, que albergaba un espacio interior de 1755 rescatado de un palacio en Damasco, con paneles de cedro pintados a mano, divanes bajos y almohadas bordadas. La embajada ofrecía recorridos al público como parte de la promoción de la cultura y las tradiciones de Kuwait (Fatma Hussein en una entrevista para la revista Harper Bazar Arabia, 2017, https: / /www.harpersbazaararabia.com/people/news / first-among-equals-fatma-hussein).

${ }^{9}$ [Desde su creación, la revista ha sido testigo de una modernización constante en temas y secciones, en línea con los avances tecnológicos. Kuwait solía ser en el pasado un ejemplo en la región del Golfo en los ámbitos de la cultura y el arte].

${ }^{10}$ [Una nueva clase culta de élite, compuesta por beduinos independientes, hijos de comerciantes y antiguos marineros que no tenían afiliación tribal (y que) obtuvieron posiciones en el gobierno y eran leales al Estado].

${ }^{11}$ [La modernización afectó enormemente a las mujeres kuwaitíes al exigirles revisar su estatus en la sociedad. Como resultado, muchas mujeres kuwaitíes intentaron mejorar su estatus social y político. Las mujeres más activas aprovecharon el cambio social y lo utilizaron para ocupar su lugar en la sociedad kuwaití. Al principio, acogieron la modernización en sus aspectos de innovación y occidentalización. Desarrollaron su estatus educativo asistiendo a universidades y estudiando en el extranjero, y al mismo tiempo adoptaron influencias culturales occidentales, que se hicieron visibles en el rechazo al velo y la imitación de la vestimenta occidental. Después de eso, buscaron en otras sociedades, especialmente sociedades árabes occidentalizadas como Egipto y Líbano, e inspeccionaron los movimientos de emancipación de mujeres allí y comenzaron a cuestionar la posición de las mujeres en su propio contexto].

12 [Se garantizará la libertad de opinión y de investigación científica. Toda persona tendrá derecho a expresar y propagar su opinión verbalmente, por escrito o de otro modo, sujeta a las condiciones y estipulaciones especificadas por la ley].

${ }^{13}$ La ley de Dios es la guía indiscutible y predominante para la conducta personal y el derecho de familia, mientras que el derecho secular rige los asuntos políticos y legales.

${ }^{14}$ [Bajo la ley de sharia el concepto de libertad es diferente del concepto de libertad en Occidente. Bajo la ley sharia debe haber un equilibrio entre la libertad y la responsabilidad basado en el mandato que señala "manda lo que es correcto y prohíbe lo que es malo" y "aquello que no te haga daño ni a ti mismo ni a los demás”].

${ }^{15}$ La compañía Kuwait Airways adoptó este nombre en 1955 después de que el gobierno invirtiera un cincuenta por ciento del capital original. En 1963 pasó a manos del gobierno de Kuwait y sus rutas aéreas incluían tanto capitales del Medio Oriente como otros destinos en Asia y Europa. Sorprende por ejemplo que algunas de las rutas de la compañía incluyeran vuelos a Bagdad, Baréin, Beirut, Bombay, Damasco, Doha, El Cairo, Fráncfort, Ginebra, Jerusalén, Karachi, Londres, París y Teherán.

${ }^{16}$ [El elemento islamista/tribal de la sociedad kuwaití consideraba la modernidad, o la occidentalización asociada con ella, como un concepto peligroso que corrompía el estatus de las mujeres en Kuwait y las alejaba de su lugar. Los defensores de la modernidad, por otro lado, consideran que la modernización no es perjudicial].

${ }^{17}$ [Nada se considera más indecoroso que las acciones o el comportamiento de una mujer como objeto de chismes de la ciudad, incluso de una manera relativamente inocente, y el velo por tanto ha permitido a las mujeres preservar su anonimato cuando salen de sus casas. Si el rumor o el chisme refleja seriamente la virtud de una mujer de buena familia, la mujer es arruinada (socialmente)]. 
${ }^{18}$ [La segregación y un estricto código de vestimenta islámica han resurgido, lo mismo que el tema del niqb (velo que cubre toda la cara) [...] Me pregunto qué ha sucedido con la iniciativa intelectual de los pensadores y académicos musulmanes, quienes deberían tener nuevas ideas para saber cómo preservar nuestra identidad sin abandonar el progreso social, intelectual y psicológico].

\section{Referencias}

Abu-Hakima, A (1982). The Modern History of Kuwait 1750-1965. Intl Book Centre.

Al-Mughni, H. A. (2000). Women in Kuwait: the politics of gender. Londres: Saqi Books.

Al-Sabah, A. E. (2017). Sharia democracy and the Kuwaiti Constitution. Londres: Arabian Publishing.

Alsuwailan, Z. (2006). The impact of societal values on Kuwaiti women and the role of education.

Tennessee: University of Tennessee. Disponible en: https: / / trace.tennessee.edu/utk_graddiss/1631

Arasoghli, A. (1986). "Education and Employment in Kuwait". Kuwaiti women: 25 years of independence (1961-1986). VIII (36), 2-6.

Arab Times. (19 de mayo de 2013). Kuwaiti youth main driver of growth. Disponible en: https: / /www.pressreader.com/

Aubry, A. (2017). First among equals: Meet Fatma Hussein. Harper's Bazaar Arabia. Disponible en: https: / / www.harpersbazaararabia.com/people/news/first-among-equals-fatma-hussein

Barakat, H. (1993) The Arab world: society, culture, and state. California: University of California Press.

Constitution of Kuwait (1962). Kuwait's Constitution of 1962. Reinstated in 1992. Disponible en: https://www.constituteproject.org/constitution/Kuwait_1992.pdf?lang=en

Cornejo, A (1994). Escribir en el aire. Ensayo sobre la heterogeneidad socio-cultural en las literaturas andinas. Lima: Horizonte.

Freeth, Z. (1956). Kuwait was my home. Londres: George Allen \& Unwin.

García Canclini, N. (1989). Culturas híbridas: Estrategias para entrar y salir de la modernidad. México: Grijalbo.

Hasam, M. (1996). Women and development: cultural and social dimensions. Al-Zamaan Magazine.

Ismael, J. (1982). Kuwait: social change in historical perspective. Nueva York: Syracuse University Press.

Khedr, A. A. (3 de octubre de 2019). Kuwait legal system and research. Disponible en: https:// www.nyulawglobal.org/globalex/Kuwait1.html

Kuwait Times. (1960-1969). National Library of Kuwait. (Print)

Nath, K. (1978). Education and employment among Kuwaiti women. En: L. Beck \& N. Keddie (eds.). Women in the Muslim world. Cambridge: Harvard University Press.

Olimat, M. S. (2009). Women and politics in Kuwait. Journal of International Women's Studies, 11(2), 199-212. Disponible en: http://vc.bridgew.edu/jiws/vol11/iss2/13

PBS NewsHour. (30 de junio de 2006). Women's suffrage, reformist victory mark Kuwaiti elections. Disponible en: https://www.pbs.org/newshour/politics/middle_east-jan-june06kuwait_06-30

Rejwan, N. (2003). A wild goose chase: to cope, must Islam ‘westernize’? En: M. J. Thompson (ed.). Islam and the west: critical perspectives on modernity. Maryland: Rowman \& Littlefield.

Rugh, W. (1987). The Arab Press: news media and political process in the Arab world. Nueva York: Syracuse University Press.

Tétreault, M. A. (2000). Stories of Democracy: Politics and Society in Contemporary Kuwait. New York, NY: Columbia University Press.

Tétreault, M. A. (2001). A State of two minds: state cultures, women, and politics in Kuwait. International Journal of Middle East Studies, 33(2), 203-220.

Recibido: octubre de 2019 / Aprobado: 22 de diciembre de 2019 